\title{
Photoinactivation of mycobacteria to combat infection diseases: current state and perspectives
}

\author{
Margarita Shleeva $^{1}$ (D) $\cdot$ Alexander Savitsky ${ }^{1} \cdot$ Arseny Kaprelyants $^{1}$ \\ Received: 1 April 2021 / Revised: 4 May 2021 / Accepted: 9 May 2021 / Published online: 17 May 2021 \\ (C) The Author(s), under exclusive licence to Springer-Verlag GmbH Germany, part of Springer Nature 2021
}

\begin{abstract}
The spread of multi-drug-resistant bacterial strains causing serious infectious diseases dictates the development of new approaches to combat these diseases. In addition to drug resistance, the important causative agent of tuberculosis (Mycobacterium tuberculosis (Mtb)) is able to persist asymptomatically in individuals for many years, causing latent forms of tuberculosis. In such a dormant state, $M t b$ cells are also resistant to known antibiotics. In this regard, photodynamic inactivation (PDI) could be an effective alternative to antibiotics as its action is based on the generation of active forms of oxygen independently on the presence of specific antibiotic targets, thereby inactivating both drug-resistant and dormant bacteria. In this review, we summarise examples of the application of PDI for the elimination of representatives of the genus Mycobacteria, both in vitro and in vivo. According to published results, including photosensitisers in the PDI regime results in a significantly higher lethal effect. Such experiments were mainly performed using chemically synthesised photosensitisers, which need to be transported to the areas of bacterial infections, limiting PDI usage by surface (skin) diseases. In this regard, endogenous photosensitisers (mainly porphyrins) could be used to solve the problem of transportation. In vitro experiments demonstrate the effective application of PDI for mycobacteria, including $M t b$, using endogenous porphyrins; the intracellular contents of these substances can be elevated by administration of 5-aminolevulenic acid, a precursor of porphyrin synthesis. Photodynamic inactivation can also be used for dormant mycobacteria, which are characterised by high levels of endogenous porphyrins. Thus, PDI can effectively eliminate drug-resistant mycobacteria. The exploitation of modern light-transmitting techniques opens new possibilities to use PDI in clinical settings.
\end{abstract}

\section{Key points}

- The potential effects of photodynamic inactivation of mycobacteria are critically reviewed.

-Approaches to photoinactivation of mycobacteria using exogenous and endogenous photosensitisers are described.

-Prospects for the use of photodynamic inactivation in the treatment of tuberculosis are discussed.

Keywords Mycobacteria - Photodynamic inactivation - Antibacterial photodynamic therapy $\cdot$ Mycobacterium tuberculosis . Porphyrins

\section{Introduction}

Mycobacterium is a genus of the Gram-positive Actinobacteria. Some members of this genus are the causative agents of a number of clinically significant diseases

Margarita Shleeva

margoshleeva@gmail.com

1 Federal Research Centre "Fundamentals of Biotechnology" of the Russian Academy of Sciences, A.N. Bach Institute of Biochemistry, Moscow, Russia (mycobacteriosis). Among the species pathogenic for humans (60 non-tuberculosis species in total), the most known ones are Mycobacterium avium, Mycobacterium intracellulare, Mycobacterium kansasii, Mycobacterium abscessus, Mycobacterium marinum, Mycobacterium ulcerans, Mycobacterium fortuitum, Mycobacterium chelonae and Mycobacterium leprae. Most pathogenic mycobacteria are responsible for lung infections, although occasional cases involve lymph nodes, bones and joints, the skin and wounds (Gonzalez-santiago and Drage 2015). However, the most important disease caused by mycobacteria is tuberculosis (TB), which is caused by Mycobacterium tuberculosis (Mtb). 
Tuberculosis remains the top infectious killer worldwide and caused 1.5 million deaths in 2019, comparably to the number of victims of coronavirus infection (1.8 million in 2020). In 2019, 10 million new cases of TB have been registered (https://www.who.int/ru/news-room/fact-sheets/detail/ tuberculosis). This situation is complicated by the high and growing level of M. tuberculosis antibiotic-resistant strains and multidrug-resistant tuberculosis (MDR-TB), resistant to antibiotics of the first line (isoniazid and rifampicin). Thus, approximately 200,000 people with MDR-TB were registered in 2019, a $10 \%$ increase from 2018. For those patients, second-line antibiotics (such as fluoroquinolones or kanamycin) should be used; however, such treatment is expensive and of long duration (up to 20 months). Worldwide, only $57 \%$ of MDR-TB patients are currently (2019) successfully treated. Another growing problem is the appearance and spreading of so-called extremely drug resistant (XDR-TB) Mtb strains, which exhibit resistance to the first line and to any of the fluoroquinolones, as well as to at least one of three injectable second-line drugs (i.e. kanamycin). The percentage of patients with MDR/XDR TB varies from 3 to 27\% globally, depending on the country. According to the CDC (Center for Disease Control and Prevention) (https://www.cdc.gov/tb/), more than 2.6 million people could die from MDR TB each year by 2050 if the dissemination of resistant strains does not stop (https:// www.cdc.gov/tb/). Evidently, due to the rapid emergence of new TB mutants and the spread of existent MDR/XDR, new approaches are needed.

A substantial problem in TB epidemiology is connected with the high number of people having latent forms of tuberculosis (up to $1 / 4$ of the global population https://www.who. int/ru/news-room/fact-sheets/detail/tuberculosis). Latent tuberculosis (LTB) is an asymptomatic form of TB, where the pathogen could be carried by infected people in a dormant state without symptoms of the disease for a long time, the socalled latent tuberculosis infection (LTBI). Approximately 5\% of latently infected individuals can develop active TB during their lifetimes and become contagious, which negatively influences the epidemiological situation. This number increases by several times in patients with immunosuppression due to either HIV/AIDS or immunosuppression therapy. This situation dictates the necessity of curing LTB, as each undetected case with active TB may potentially infect up to 15 people per year (Nechaeva 2018). There is a general belief that TB latency is the clinical manifestation of an intrinsic property (dormancy) of $M t b$. Several studies have shown the ability of mycobacteria to produce dormant forms either in culture or inside macrophages or animal tissues (Biketov et al. 2000; Dhillon et al. 2004; Mukamolova et al. 2010; Shleeva et al. 2011; Broger et al. 2017; Peddireddy et al. 2017). These forms are characterised by the long-lasting state with low metabolic activity. In several in vitro models, dormant $M t b$ cells with negligible metabolic activity were generated, and their resistance to known antituberculosis drugs was found (Kaprelyants et al. 2018). This is not surprising, since many drugs are based on the inhibition of biosynthetic pathways such as protein, nucleic acid or cell wall polymer synthesis, eventually resulting in cell death due to unbalanced metabolism. In this line, dormant cells would escape the activity such as "biochemical drugs", although they still possess appropriate targets (proteins). It has been suggested that inactivation of dormant cells could be due to unspecific antibacterials produced by pathogenic cells, self-killing effects. Among such substances, active forms of nitrogen and oxygen as well as some carbonic compounds, which could be generated inside of cells due to the activity of some enzymes and the conversion of the appropriate prodrugs, are discussed. Currently, several examples of the application of this approach can be found (Kaprelyants et al. 2018); however, their applicability for curing of LTB patients has not been demonstrated. Theoretically, because of unspecificity, such "undirect" prodrug compounds should be also active against resistant strains of $M t b$.

Another approach for eliminating MDR-TB or dormant bacteria could be the application of physical factors that simultaneously influence several bacterial targets, regardless of the fact whether they are in an active or an inactive state. One of the possible factors is the light used in photodynamic inactivation (PDI); this promising approach which will be discussed below in relation to pathogenic and nonpathogenic mycobacteria.

\section{Photodynamic inactivation of bacteria-general aspects}

Antimicrobial photodynamic inactivation (aPDI) is based on the photoinactivation of bacteria in the presence of certain compounds named "photosensitisers" (PS). In classical considerations, there are two main mechanisms of PDI: (1) Type I is based on reactive oxygen species (ROS) generation upon illumination, which readily react with molecules essential for the live cycle of the cells and destroy cell metabolism, resulting in cell death. (2) Type II is based on the photogeneration of highly reactive singlet oxygen spices as the primary process, after which ROS can be generated or singlet oxygen can directly interact with cell molecules. Currently, the role of the third mechanism, based on local overheating (hyperthermia) of different cell compartments due to photo absorption, is discussed. This mechanism has become dominated in the case of different types of nanoparticles used for PDI (Yoo et al. 2021). The development of bacterial resistance to PDI is believed to be unlikely due to the non-specific damage caused by ROS, ${ }^{1} \mathrm{O}_{2}$ or local overheating (Maisch 2007; Bruce-Micah et al. 2009). Although the exact mechanism of aPDI is still unknown, in 
most cases of bacterial cell killing, leakage of intracellular material is a critical feature, and the localisation of photosensitisers in the cell wall is essential for the overall efficiency of aPDI. Nevertheless, in some cases, no significant leakage of intracellular metabolites can be observed after aPDI treatment for example from Listeria monocytogenes, and at the same time, no viable cells can be detected by colonyforming tests (Romanova et al. 2003).

Perhaps the first application of PDI in bacteria was documented in late nineteenth century, when Nieles Finsen published the results on curing a type of skin tuberculosis (lupus vulgaris) by phototherapy. In 1903, he was awarded the Nobel Prize for this achievement. Much later, the mechanism behind this effect was uncovered, and PDI inactivation of the causative pathogen $(M t b)$ due to porphyrin light absorption was suggested (Møller et al. 2005).

Since Finsen's discovery, PDI application has been developed only slowly and ranks behind the intensive progression of antibiotics usage in medicine. However, recently, in connection with the global spreading of antibiotic-resistant strains, interest in PDI has significantly increased. To date, a substantial number of in vitro studies have been conducted in respect to the application of PDI for bacterial inactivation, including both Gram-positive and Gram-negative species. Most studies include the application of exogeneous PS of different structures (Malik et al. 1990; Wainwright 1998; Ashkenazi et al. 2003; Liu et al. 2015; Tim 2015), mainly phenothiaziniums, pthalocyanines, porphyrins and fullerenes, among others.

Generally, Gram-positive bacteria are more susceptible to PS and PDI than Gram-negative ones because of the better delivery of PS into the cell, which is due to the simple cell wall organisation in Gram-positive bacteria (Hamblin and Hasan 2004). However, the application of charged PS and permeabilising agents can improve the effectiveness for different types of bacteria. Another approach is the usage of PS conjugates, which facilitate the penetration of the PS molecule into the bacterial cell. To improve PS specificity, antibody-PS conjugates have been synthesised, and their effectiveness in the elimination of Pseudomonas aeruginosa has been demonstrated in vivo in mice infection models (Tim 2015).

The use of endogenous PS produced by the bacterium is another approach for PDI application. Here, endogenous porphyrins naturally occurring in significant amounts in some bacteria of medical significance have been explored to eliminate Propionibacterium acnes responsible for acne or Helicobacter pylori, the causative agent of several diseases, including ulcer and gastritis (Hamblin and Hasan 2004).

Whilst rather limited, some studies have confirmed PDI effectiveness for bacteria elimination in animal models (including pathogenic Pseudomonas species, Escherichia coli, Staphylococcus aureus) (Hamblin and Hasan 2004; Jori et al. 2006).
The abovementioned laboratory studies have been expanded toward the application of PDI in a clinical context. Photodynamic therapy for treatment of bacterial infections is effective against gastric infections caused by Helicobacter pylori and Propionibacterium acnes and against some other skin infections, as well as localised surgical infections and leg and foot ulcers. Several clinical trials of PS-mediated PDI application have been performed (Wainwright et al. 2017).

Detailed information on PDI and PS application for the eradication of different bacteria in vitro, in vivo and in clinic can be found in a number of reviews (Jori et al. 2006; Wainwright 2009; Kharkwal et al. 2011; Harris and Pierpoint 2012; Oppezzo and Forte Giacobone 2018).

Below, we provide a more detailed review on the application of PDI in respect to mycobacteria, including the usage of exogenous and endogenous PSs.

\section{Exogenous photosensitisers for antimycobacterial PDI}

The efficiency of PDI is influenced by the concentration of the photosensitiser and the light dose. The requirements for a photosensitiser are high phototoxicity, with a high yield of singlet oxygen or free radicals (that are lethal to the microbe), which must be combined with low dark toxicity, and it must either accumulate inside bacterial cells or bind to the bacterial cell wall (Liu et al. 2015). Mycobacteria have a complex cell wall, and several studies have investigated photosensitisers that would effectively bind to this type of bacteria. Table 1 shows the exogenous PSs are presented that were used in mycobacterial PDI experiments.

\section{Porphyrin derivatives}

Photosensitisers of the porphyrin structure are most often used for this purpose (Table 1). Porphyrins are among the main photosensitisers (PS) used in microorganism photoinactivation studies. Experiments in vitro have shown that Mycobacteroides abscessus subsp. Massiliense and Mycolicibacterium fortuitum were 100 times more susceptible to white-light illumination when cationic porphyrins were used (Guterres et al. 2019). However, the bactericidal action of the porphyrin derivatives containing the $\mathrm{Pt}$ (II) complexes (3-PtTPyP and 4-PtTPyP) totally inhibited the growth of Mycobacteroides abscessus subsp. Abscessus, Mycolicibacterium fortuitum, Mycobacteroides abscessus subsp. Massiliense and Mycolicibacterium smegmatis strains in the MIC and 2xMIC concentrations in the first $48 \mathrm{~h}$ after white-light illumination. They were more effective when the complexes were coordinated with the nitrogen atom in the meta position (Rossi et al. 2020). To detect the possible ROS produced by porphyrins during the photoinactivation 


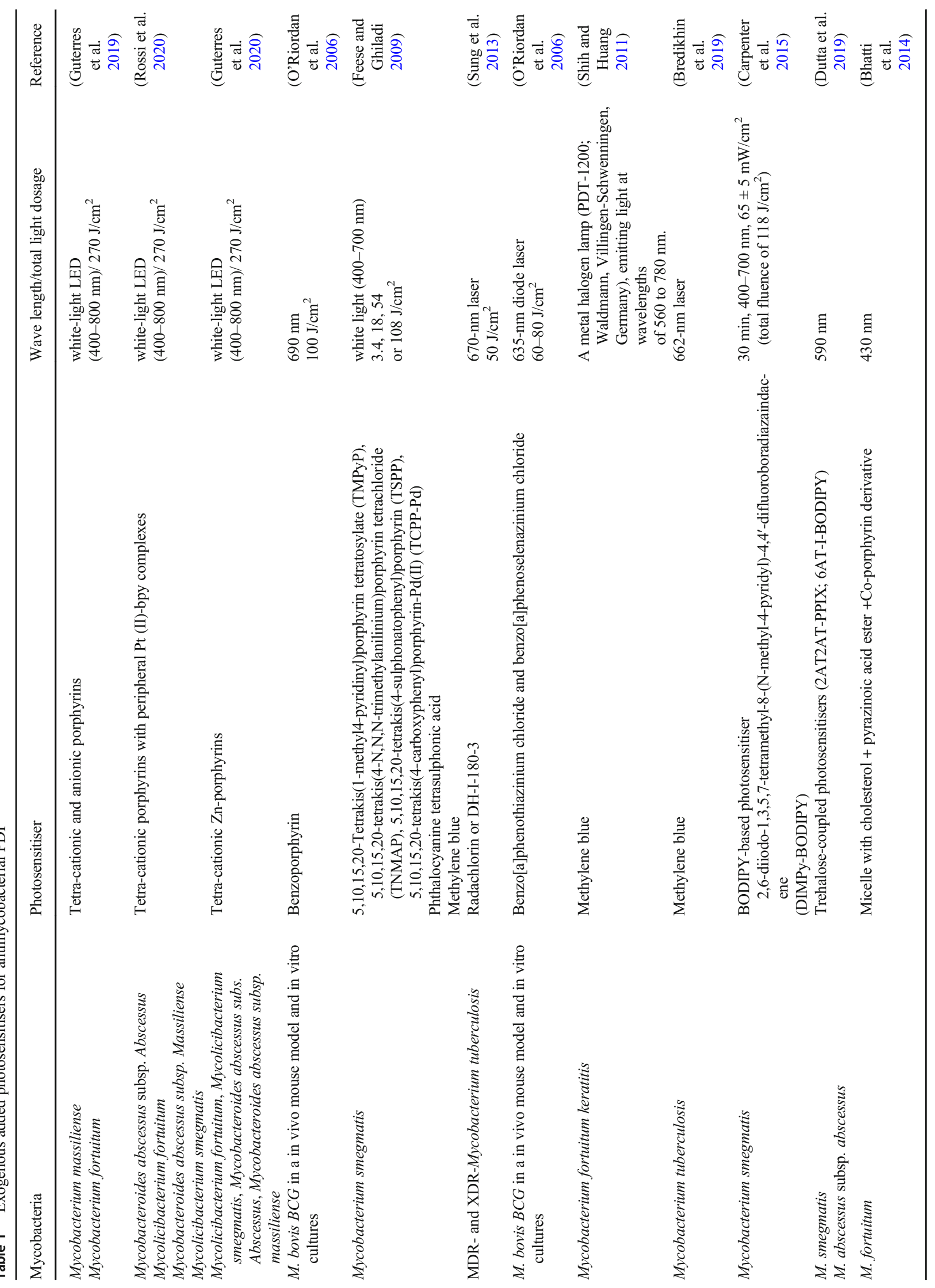


process, the scavenger assay was used. The Pt (II) porphyrins reduced the photo-oxidant activity in the presence of the ascorbic acid $\left({ }^{1} \mathrm{O}_{2}\right.$ scavenger) (Rossi et al. 2020).

Another cationic metalloporphyrin containing zinc (II) ions is a prospective PS for mycobacterial photoinactivation. The type of metal centre ion is important for successful PDI. Via atomic force microscopy analysis, the changes in the morphology and adhesivity of M. smegmatis cells under white-light irradiation in the presence of porphyrins containing $\mathrm{Zn}$ (II) ions could be shown; the authors suggested that these effects are due to membrane photodamage (Guterres et al. 2020).

In general, anionic porphyrins have a considerably lower PDI effect on mycobacteria (Guterres et al. 2019). These findings were confirmed in another study (Feese and Ghiladi 2009), which evaluated the lethal effect of various photosensitisers [5,10,15,20-tetrakis (1-methyl-4-pyridinyl) porphyrin tetratosylate (TMPyP); 5,10,15,20-tetrakis (4$\mathrm{N}, \mathrm{N}, \mathrm{N}$-trimethylanilinium) porphyrin tetra-chloride (TNMAP); 5,10,15,20-tetrakis (4-sulphonatophenyl) porphyrin (TSPP); 5,10,15,20-tetrakis (4-carboxyphenyl) porphyrinPd (II)(TCPP-Pd) at different doses on M. smegmatis in vitro. This work demonstrated that, in contrast to the use of anionic PS, using cationic photosensitisers in the nanomolar concentration range resulted in a 5-6 log of CFU reduction, which approximately corresponds to the destruction of $99.99 \%$ viable cells of M. smegmatis (Feese and Ghiladi 2009). The decreased activity of anionic PS might be due to their weak ability to bind with the negatively charged cell surface.

Future in vivo studies on the use of PDI to clear mycobacterial infections should focus on the application of highly cationic PSs, with the caveat that other factors, such as compound lipophilicity, aggregation or localisation, also need to be considered.

Chlorins, which are structurally similar to porphyrins, have also been used as PS. They are characterised by a large heterocycle aromatic ring whose core consists of four pyrroles linked in pairs by four methyl bonds. In some studies, radachlorine (based on a modified mixture of chlorins from the microalga Spirulina) has been used as a photosensitiser, which is characterised by absorption peaks at $402,502,532$, 608 or $662 \mathrm{~nm}$. In another study, drug-susceptible, resistant (MDR) and extensively drug-resistant (XDR) M. tuberculosis clinical stains were irradiated with a non-thermal laser for $500 \mathrm{~s}\left(50 \mathrm{~J} / \mathrm{cm}^{2}\right)$ in the presence of either radachlorine or chlorin-based DH-I-180-3 (Sung et al. 2013). Irrespective of the drug resistance pattern, the inactivation levels in the strains tested were the same in PDT (Sung et al. 2013). However, prolonged irradiation did not completely linearly inactivate the $M t b$, allowing a low number of bacilli survivors ( $3 \log 10$ CFU). Pulse PDT (intermittent PDT and repeated PDT), which irradiates $M t b$ at the dose of $20 \mathrm{~J} / \mathrm{cm}^{2}$, followed by incubation for $2 \mathrm{~h}$, demonstrated a better inactivation than continuous PDT with prolonged irradiation and tended to generate a linear inactivation in PDT. According to calculations, $1 \log 10 \mathrm{CFU}$ of $M t b$ is inactivated with $11.39 \mathrm{~J} / \mathrm{cm}^{2}$ of irradiation in the presence of radachlorine, regardless of the drug resistance level (Sung et al. 2013). This result was confirmed in another experiment with the laboratory strain $M t b$ H37Rv (Bredikhin et al. 2018).

\section{Methylene blue (MB)}

The second most commonly used photosensitiser to kill mycobacteria is methylene blue. In contrast to porphyrin derivatives, which require long incubation periods for photosensitisation, phenothiazinium derivatives such as MB yield results more quickly. It was found that with PDT, in the presence of $0.01 \% \mathrm{MB}$ and with an energy density of 100 $150 \mathrm{~J} / \mathrm{cm}^{2}$, at least $4 \log 10 \mathrm{CFU}$ in the M. fortuitum suspension were killed (Shih and Huang 2011).

For M. smegmatis, it has been demonstrated in vitro that MB is effective depending on the MB concentration. Thus, at a concentration of $75 \mu \mathrm{M}$ and 30-min illumination, a $4 \log$ $\mathrm{CFU}$ reduction was observed, whilst at an $\mathrm{MB}$ concentration of $2.5 \mu \mathrm{M}$, the decrease in CFU was only $2 \log$ (Feese and Ghiladi 2009).

It is important that the Mycobacterium smegmatis strains sensitive and resistant to ciprofloxacin are sensitive to PDI by red laser light at $\mathrm{X}=630 \mathrm{~nm}$ in the presence of $\mathrm{MB}$ at doses of $5(15 \mu \mathrm{M})$ and $30 \mu \mathrm{g} / \mathrm{ml}(90 \mu \mathrm{M})$. A higher level of susceptibility to PDI-MB is characteristic of ciprofloxacin-resistant strains of M. smegmatis (Shim et al. 2016).

The PDI of Mycobacterium tuberculosis H37Rv was effective in the presence of $1 \mu \mathrm{g} / \mathrm{ml}(3 \mu \mathrm{M}) \mathrm{MB}$. In this case, a 1 $\log 10$ CFU decrease was obtained after illumination by laser with a wavelength of $662 \mathrm{~nm}$ and with the lowest density of the dose of light energy $\left(46.9 \mathrm{~J} / \mathrm{cm}^{2}\right)$ (Bredikhin et al. 2019).

\section{BODIPY-based photosensitisers}

Borodipyrrine luminophores, or BODIPY, are attractive for PDI because they exhibit intense chromophore and fluorescent properties and high resistance to aggressive environmental factors (Kamkaew et al. 2013). In the presence of the BODIPY-based photosensitiser 2,6-diiodo-1,3,5,7tetramethyl-8 - (N-methyl-4-pyridyl) - 4, 4' difluoroboradiazaindacene (DIMPy- BODIPY), the number of viable $M$. smegmatis cells decreased by $\sim 4 \log$ CFU at $1 \mu \mathrm{M}$ PS, $\sim 3.3 \log \mathrm{CFU}$ at $0.5 \mu \mathrm{M}$ and $\sim 2 \log \mathrm{CFU}$ at $0.25 \mu \mathrm{M}$ of DIMPy-BODIPY after illumination with visible light (Carpenter et al. 2015).

To increase the effectiveness of PS, trehalose-coupled photosensitisers (2AT2AT-PPIX; 6AT-I-BODIPY) have been developed. These compounds more efficiently penetrate the mycomembrane, which results in an increased PDI effect at $590 \mathrm{~nm}$ irradiation (Dutta et al. 2019). 


\section{Nanoparticles}

The use of nanoparticles (NPs) can overcome some drawbacks of organic photosensitisers, such as low solubility, resulting in a more efficient delivery to the cells, high light absorptivity and lower photobleaching during PDI. Nanoparticles generally penetrate the cells by passive endocytosis. Recently, several aPDI studies of NPs applications toward resistant strains have been performed (Bekmukhametova et al. 2020). Silver and other metals as well as metal oxide NPs can be efficiently used for sterilisation (Yin et al. 2015). Under near-infrared illumination, polymersilver core-shell NPs demonstrate photohyperthermic silverion release and bactericidal effect against both Gram-positive and Gram-negative bacteria (Huo et al. 2013). Micelles with toluidine blue can efficiently be used for the treatment of mixed biofilms of wounds. In case of biofilms of grampositive $P$. aeruginosa, gram-negative $S$. aureus and their mixed cultures, the reduction of bacterial survival reached $3.4 \log 10 \mathrm{CFU}$ for $S$. aureus and $2.8 \log 10 \mathrm{CFU}$ for $P$. aeruginosa (Usacheva et al. 2016). Regarding M. fortuitum, a $100 \%$ lethal rate has been observed for NPs that contained porphyrin derivates (Bhatti et al. 2014).

Most PDI experiments with exogeneous PS have been conducted in in vitro, and only a few in vivo experiments have been reported. Benzoporphyrin derivatives were active PS in a mouse model of TB artificial subcutaneous granulomas infected with Mycobacterium bovis. Both extracellular and intracellular M. bovis cells were killed after exposure to 690-nm light (O'Riordan et al. 2006); these PS revealed similar effectiveness of PDI for both drug-susceptible and drug-resistant clinical Mtb strains (O'Riordan et al. 2006). The authors estimated that more than $74 \%$ of Mycobacterium bovis BCG was killed after illumination at $690 \mathrm{~nm}$ in the presence of benzoporphyrin derivatives.

Using the same model of artificial granuloma sterilisation activity by PDI toward $M$. bovis, some phenothiazinium analogues, such as cationic PS, have been shown (O'Riordan et al. 2007).

In another study, M. fortuitum was eliminated after PDI in the presence of $\mathrm{MB}$ in lesions developed in experimental keratitis in rabbits. The combination of antibiotic therapy and MB-mediated PDI demonstrated greater antimycobacterial activity than antibiotic therapy alone (Shih and Huang 2011).

\section{Endogenous photosensitisers for antimycobacterial PDI}

The use of endogenous PS seems to be superior to that of exogenous PS, as this approach does not require the administration of potentially toxic chemical substances. The delivery of exogenous PS to the target bacteria in vivo also limits the application of exogenous PS. There are several examples of photoinactivation of mycobacteria on the basis of endogenous PS (Table 2). Thus, blue light ( $405 \mathrm{~nm}$ ) can effectively (up to $100 \% \mathrm{CFU}$ ) inhibit the growth of M. smegmatis in vitro (Guffey et al. 2013). Whilst the authors did not speculate on the possible mechanism, it could be suggested that endogenous porphyrins or cytochromes could be involved in PDI (both have a Soret band of around $405 \mathrm{~nm}$ ). However, the effect of illumination with $405 \mathrm{~nm}$ on M. smegmatis could not be confirmed in a later study (Shleeva et al. 2019), most likely because of technical details. Thus, in the experiment of Guffey et al. (2013), PDI was tested on bacteria plated on a solid medium surface in contrast to illumination of the same bacteria in liquid medium (Shleeva et al. 2019). Possibly, the agar surface, as a stressful factor, could enhance cell damage after illumination. In addition, the colony on the surface contains cells with a variety of physiological states, characterised by different concentrations of endogenous porphyrins. Indeed, low concentrations of porphyrins accumulate in actively growing $M$. smegmatis in contrast to the significant amount of porphyrins in non-replicative cells (Shleeva et al. 2020).

Illumination of another mycobacterium (Mycobacterium terrae) by $405-\mathrm{nm}$ blue light resulted in the inactivation of the bacteria by $4-5 \log 10 \mathrm{CFU}$, whilst neither the particular physiological state of bacteria in these experiments nor the target were established (Murdoch et al. 2012).

A moderate effect (decrease of CFU by $35 \%$ ) of blue light at $464 \mathrm{~nm}$ on M. smegmatis has been reported (Guffey et al. 2014). Although the target(s) for these wavelengths could not be established, involvement of menaquinone as a component of the respiratory chain is suggested.

The bacterial inhibition in cited works (Guffey et al. 2013; Guffey et al. 2014) requires rather high doses of radiation, which might exceed safe levels of exposure for the host. The radiation dose to inactivate $M$. smegmatis could be decreased with the use of 850-nm illumination. However, the effectiveness of such illumination was not sufficient to kill all mycobacteria (Guffey et al. 2014). The mechanism behind bacterial inactivation under $850 \mathrm{~nm}$ remains unclear.

Much less information could be found on "endogenous" PDI with M. tuberculosis, although the first PDI application to cure $M t b$ was conducted by Finsen in 1898 (see above).

A decrease in CFU by $1 \log 10$ for M. tuberculosis has been shown after illumination with light of $662 \mathrm{~nm}$ (Bredikhin et al. 2019). The target corresponding to this wavelength is not obvious, as porphyrins have an absorption maximum at 550-600 nm. Most likely, chlorins (absorption maximum approximately $660 \mathrm{~nm}$ ) are responsible; however, there is no information on chlorin accumulation during the growth of $M t b$. Illumination of Mtb cell suspensions at $565 \mathrm{~nm}$ (corresponding to porphyrin absorption) did not significantly decrease the number of viable bacteria estimated by the MPN (most probable numbers) assay in liquid medium (Shleeva 
Table 2 Photodynamic inactivation of mycobacteria (may be due to endogenous PS)

\begin{tabular}{|c|c|c|c|}
\hline Mycobacteria & Wave length & Efficiency & Reference \\
\hline Mycobacterium smegmatis (colonies) & $405 \mathrm{~nm}$ & up to $100 \% \mathrm{CFU}$ & (Guffey et al. 2013) \\
\hline Mycobacterium terrae & $405 \mathrm{~nm}$ & $4-5 \log 10 \mathrm{CFU}$ & (Murdoch et al. 2012) \\
\hline Dormant Mycobacterium smegmatis & $395,475,575 \mathrm{~nm}$ & $3 \log 10$ & (Shleeva et al. 2019) \\
\hline Dormant Mycobacterium smegmatis & $532 \mathrm{~nm}$ & $3-4 \log 10$ & (Shleeva et al. 2020) \\
\hline Skin Mycobacterium tuberculosis & $\begin{array}{l}\text { Glass lenses (absorbing wavelength }<340 \mathrm{~nm} \text { ) } \\
\text { ultraviolet radiation }\end{array}$ & not defined & (Møller et al. 2005) \\
\hline M. smegmatis & $464,850 \mathrm{~nm}$ & decrease of CFU by $35 \%$ & (Guffey et al. 2014) \\
\hline M. tuberculosis & $662 \mathrm{~nm}$ & $1 \log 10$ & (Bredikhin et al. 2019) \\
\hline
\end{tabular}

et al. 2002), which allows the determination of maximum viable bacteria after exposure to stress (Fig. 1).

To enhance the concentration of endogenous PS in several cases, 5-aminolevulenic acid (ALA) (a precursor of porphyrin synthesis) have been added upon cultivation of mycobacteria. In this case, an increase in the intracellular concentration of uroporphyrin and coproporphyrin has been shown for Mycobacterium smegmatis and Mycobacterium phlei in the stationary phase. The major porphyrin was identified as coproporphyrin (Bruce-Micah et al. 2009; Shleeva et al. 2020). The use of the ALA-PDI approach has been demonstrated for the inactivation of M. smegmatis cells in vitro, when illumination by $532-\mathrm{nm}$ light resulted in a $2.5 \log 10$ drop in viability (CFU) (Shleeva et al. 2020).

Several applications of ALA-PDI including in clinic have been reported to date, mainly including mycobacteria that cause skin diseases (Table 3). Among them are Mycobacterium chelonae subsp. abscessus, M. gordonae, Mycobacterium gilvum and M. fortuitum (Sun et al. 2017). In these experiments, ALA-PDI were combined with antibiotics, which resulted in absence of disease recurrence, which otherwise frequently occurs when only antibiotics are applied. The shortening of the curing time has been reported as an advantage of such an approach (Sun et al. 2017). In another study, the combination of ALA-PDI with antibiotics could successfully cure skin abscesses caused by M. fortuitum (Gong et al. 2016).

Attempts to treat swimming pool granuloma caused by $M$. marinum by PDI only or in combination with antibiotics were not successful until ALA was included in the treatment protocol. As a result, recurrence of the disease was not registered up to 7 months after treatment (Wiegell et al. 2006).

The ALA-PDI approach has been tested for the inactivation of $M$. tuberculosis cells in vitro. According to the results shown in Fig. 1, illumination of M. tuberculosis cell suspensions with $565-\mathrm{nm}$ light for $60 \mathrm{~min}$ resulted in a decrease in MPN from $2 \times 10^{7}$ to $10^{4}$ cells $/ \mathrm{ml}$ in contrast to illumination without ALA.
Another way to improve antibacterial photosensitisation by endogenous porphyrins is the activation of coproporphyrinogen oxidase (CgoX) by 2-(3-(furan-2-yl)1H-pyrazol-5-yl)naphthalen-1-ol (compound 882).

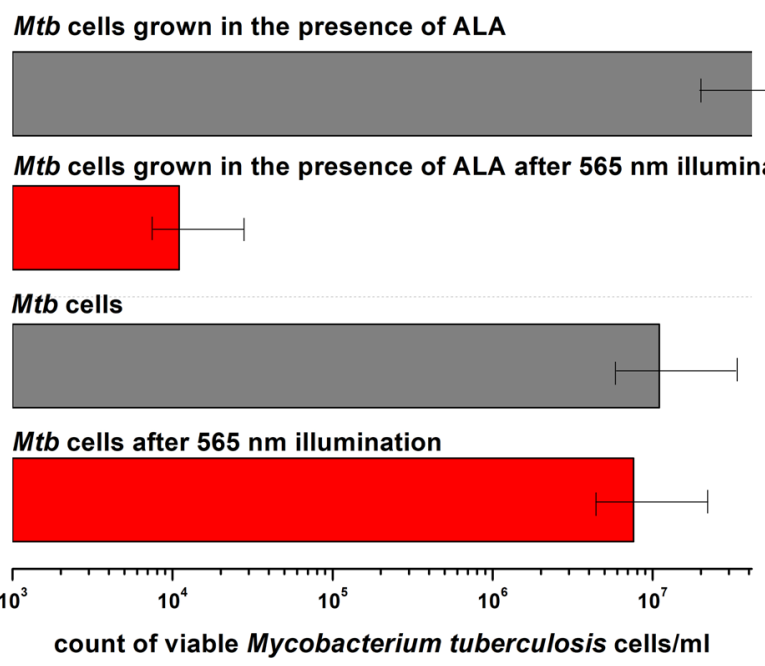

Fig. 1 Effect of $\lambda$ - 565-nm light on the survival of active $M t b$ cells grown with and without ALA. Strain M. tuberculosis H37Rv, sub-strain Pasteur, from the collection of the Central Institute for Tuberculosis (Moscow, Russia) was grown in Middlebrook $7 \mathrm{H} 9$ broth base with $0.05 \%$ Tween80 medium and ADC (Himedia, India) for 7 days. To some flasks, $3 \mathrm{mM}$ ALA was added. Suspensions of active cells with OD $=0.1$, which corresponds to ca. $10^{7}$ bacteria per $\mathrm{ml}$, were used for light inactivation experiments. For this, $100 \mu \mathrm{l}$ were pipetted in the wells of a 96-well plate (Nunc). Illuminations of the samples were performed at 565-nm lightemitting diode Solis-4C (Thorlabs, USA). Light power was verified with a Newport 2936-c power metre. Light beam was collimated to the diameter of $5 \mathrm{~mm}$, which corresponded to the diameter of wells of the 96-well plate. Illumination was performed for $60 \mathrm{~min}$. Temperature was controlled by a Fluke 80BK Type K Multimeter Thermocouple Temperature Probe directly in the microwell before and after illumination and in the presence and absence of mycobacterial suspension, at a precision of $\pm 0.2{ }^{\circ} \mathrm{C}$. Temperature was below $40{ }^{\circ} \mathrm{C}$ in the wells during all experiments. After illumination of the samples, serial 10-fold dilutions $\left(10^{-1}\right.$ to $\left.10^{-7}\right)$ were prepared in Middlebrook $7 \mathrm{H} 9$ broth base with $0.05 \%$ Tween-80 medium, and aliquots $(100 \mu l)$ were inoculated on Middlebrook 7H9 medium supplemented with ADC for MPN determination (de Man 1974). Plates were incubated under aerobic conditions at $37^{\circ} \mathrm{C}$ for 40 days 
Activation of CgoX induces the accumulation of coproporphyrin III and leads to photosensitisation of S. aureus (Surdel et al. 2017). However, this approach has not been tested in respect to mycobacteria.

Summarising, the number of studies on PDI based on endogenous PS (mainly porphyrins) is limited. It seems that the effectiveness of PDI can be sufficiently enhanced when the intracellular porphyrin concentration in mycobacteria is artificially increased by cultivation in the presence of ALA (Table 3). In cancer research, ALA is recognised as much less toxic in contrast to some exogenous PS, is permitted for many different clinical usage and can be effectively administrated to the internal organs by different ways including intravenous injection, oral administration, inhalation and topical applications (Casas 2020). Focused light delivery (see below) would provide selective PDI in this case.

Only one attempt to apply PDI in the treatment of dormant mycobacteria has been performed; dormant $M$. smegmatis formed in vitro after gradual acidification of the growth medium (Kudykina et al. 2011) are characterised by a high intracellular concentration of porphyrins. These porphyrins were represented by a mixture of uroporphyrin III and coproporphyrin III and their methyl esters, with cytoplasmic and membrane localisation (Nikitushkin et al. 2016). These dormant forms were sensitive to illumination with 395-, 475 and 575-nm light, which decreased the CFU by approximately $3 \log 10$ (Shleeva et al. 2019).

\section{Prospects for photodynamic therapy in the treatment of tuberculosis}

Despite the application of PDI in the treatment of a number of skin diseases caused by different mycobacteria, there are no studies where PDI was used against tuberculosis (apart of Finsen's work in1896). At the same time, we may envisage perspectives for PDI-tuberculosis treatment for tuberculous lesions of peripheral lymph nodes, transthoracic tuberculous empyema of the pleura, transthoracic X-ray surgical debridement of single giant parietal cavities, tuberculosis of the bronchi and bronchonodular fistulas and tuberculosis of the larynx and bladder, especially in cases of MDR pathogens. Evidently, light delivery is a critical point for PDI treatment of the abovementioned TB cases. The fibre optic looks promising to transmit excitation light to a local infected site.

In this respect, bronchoscopic photodynamic therapy as a therapeutic option in lung cancer treatment has a long history. This approach has successfully been used in advanced stages of the disease with an unresectable tumour (Moghissi and Dixon 2003). In some cases, trans-bronchoscope PDI treatment has been used for early-stage small peripheral lung cancer (Chang et al. 2020). The administration of mineral oil with a high refractive index (RI) can be used to enhance light delivery (in branched or bent anatomic structures); lipiodol, with a high RI, is used as a contrast medium for bronchography (Chang et al. 2020). In general, different kind of endoscopes used in surgery can be modified for the delivery of light with particular wavelengths. At the same time, a new approach based on flexible organic light-emitting diodes (OLEDs) as light sources for photodynamic therapy to kill bacteria adjacent to the surgery wound could be considered (Lian et al. 2019). The size of flexible OLEDs may totally cover and simultaneously illuminate the surgery wound.

\section{Conclusions}

Photodynamic inactivation is a growing and prospective approach to combat a number of infections caused by pathogenic bacteria, including antibiotic-resistant ones. Although this includes mycobacteria, PDI usage to inactivate them is rather limited in comparison with species of other genera. Nevertheless, the effectiveness of PDI has been demonstrated in both in vitro and in vivo experiments for a number of mycobacteria, including skin pathogens. Although including PS in the PDI regime results in a higher inactivation effect, the application of chemically synthesised PS is complicated by their transportation to the localised focuses of bacterial infections, which evidently limits PDI usage by surface (skin) diseases. In contrast, endogenous PS (mainly porphyrins) could solve the problem of transportation. Although mycobacteria contain some unbound porphyrins, their concentrations vary

Table 3 ALA-induced photodynamic inactivation of mycobacteria

\begin{tabular}{|c|c|c|c|}
\hline Mycobacteria & Wave length & Efficiency & Reference \\
\hline $\begin{array}{l}\text { Mycobacterium chelonae subsp. abscessus, Mycobacterium gordonae, Mycobacterium gilvum, } \\
\text { Mycobacterium fortuitum, Mycobacterium phlei, Mycobacterium smegmatis }\end{array}$ & Red light LED & $100 \%$ & (Sun et al. 2017) \\
\hline Mycobacterium fortuitum (case report) & $\begin{array}{l}\text { 635-nm laser } \\
\text { 633-nm LED }\end{array}$ & $100 \%$ & (Gong et al. 2016) \\
\hline Mycobacterium marinum & Blue light, red light & $100 \%$ & (Wiegell et al. 2006) \\
\hline Mycobacterium tuberculosis & 565-nm LED & $99.99 \%$ & This work \\
\hline Active Mycobacterium smegmatis & $532 \mathrm{~nm}$ & $2.5 \log 10$ & (Shleeva et al. 2020) \\
\hline
\end{tabular}


depending on the growth phase and other growth conditions; they are not high enough for effective PDI. This might be a reason for some controversial results published on mycobacterial sensitivity for PDI. More consistent results could be obtained if porphyrin synthesis is enhanced by administration of ALA. Indeed, Mtb cells grown in the presence of ALA exhibited a higher sensitivity for illumination corresponding to porphyrin absorption. It is important that ALA is permitted for clinical usage, and ALA-PDI revealed promising results in a clinical setting regarding the elimination of $H$. pylori (Hamblin and Hasan 2004). Apart from genetically determined resistance to antibiotics, phenotypical resistance is also an important issue in anti-infection therapy. So-called persistors, a small fraction of the bacterial population that is insensitive to antibiotics, cause problems in antibiotic treatment. Persisting cells of $P$. aeroginosa formed after incubation with ofloxacin could be eliminated by PDI in the presence of methylene blue (Oppezzo and Forte Giacobone 2018), and PDI is also effective in respect to dormant mycobacteria. Thus, PDI is effective in the elimination of bacteria with drug-resistant phenotypes, irrespective of the nature of such resistance. The application of PDI in clinical settings requires more studies in vivo and the solution of a number of technical problems connected with light transmission and delivery to foster this promising approach.

Author contribution AK, MS and AS wrote the manuscript and made a critical review. All of authors read and approved the manuscript.

Funding This work was funded by Russian Science Foundation grant 1915-00324.

\section{Declarations}

Ethical statement This article does not contain any studies with human participants or animals performed by any of the authors.

Conflict of interest The authors declare no competing interests.

\section{References}

Ashkenazi H, Malik Z, Harth Y, Nitzan Y (2003) Eradication of Propionibacterium acnes by its endogenic porphyrins after illumination with high intensity blue light. FEMS Immunol Med Microbiol 35:17-24. https://doi.org/10.1016/S0928-8244(02) 00423-6

Bekmukhametova A, Ruprai H, Hook JM, Mawad D, Houang J, Lauto A (2020) Photodynamic therapy with nanoparticles to combat microbial infection and resistance. Nanoscale 12(41):21034-21059. https://doi.org/10.1039/d0nr04540c

Bhatti M, Mchugh TD, Milanesi L, Tomas S (2014) Self-assembled nanoparticles as multifunctional drugs for anti-microbial therapies. Chem Commun 50:7649-7651. https://doi.org/10.1039/ c4cc00349g
Biketov S, Mukamolova GV, Potapov V, Gilenkov E, Vostroknutova G, Kell DB, Young M, Kaprelyants AS (2000) Culturability of Mycobacterium tuberculosis cells isolated from murine macrophages: a bacterial growth factor promotes recovery. FEMS Immunol Med Microbiol 29:233-240. https://doi.org/10.1016/ S0928-8244(00)00210-8

Bredikhin DA, Nikonov SD, Cherednichenko AG, Petrenko TI (2018) In vitro photodynamic inactivation of Mycobacterium tuberculosis by radahlorin. Tuber Lung Dis 96:5-10. https://doi.org/10.21292/ 2075-1230-2018-96-1-5-10

Bredikhin DA, Nikonov SD, Cherednichenko AG, Petrenko TI, Korbut AL (2019) In vitro photodynamic inactivation of Mycobacterium tuberculosis by methylene blue. Tuberc Lung Dis (In Russ) 97: $28-33$

Broger T, Roy RB, Filomena A, Greef CH, Rimmele S, Havumaki J, Danks D, Schneiderhan-marra N, Gray CM, Singh M, Rosenkrands I, Andersen P, Husar GM, Joos TO, Gennaro ML, Lochhead MJ, Denkinger CM, Perkins MD (2017) Diagnostic performance of tuberculosis-specific IgG antibody profiles in patients with presumptive tuberculosis from two continents. Clin Infect Dis 64: 947-955. https://doi.org/10.1093/cid/cix023

Bruce-Micah R, Hüttenberger D, Freitag L, Cullum J, Foth HJ (2009) Pharmacokinetic of ALA and h-ALA induced porphyrins in the models Mycobacterium phlei and Mycobacterium smegmatis. $\mathrm{J}$ Photochem Photobiol B Biol 97:1-7. https://doi.org/10.1016/j. jphotobiol.2009.07.004

Carpenter BL, Situ X, Scholle F, Bartelmess J, Weare WW, Ghiladi RA (2015) Antiviral, antifungal and antibacterial activities of a BODIPY-based photosensitizer. Molecules 20:10604-10621. https://doi.org/10.3390/molecules200610604

Casas A (2020) Clinical uses of 5-aminolaevulinic acid in photodynamic treatment and photodetection of cancer: A review. Cancer Lett 490: 165-173. https://doi.org/10.1016/j.canlet.2020.06.008

Chang H, Liao KS, Hsieh Y (2020) Bronchoscopic light delivery method for peripheral lung cancer photodynamic therapy. J Thorac Dis 12: 3611-3621. https://doi.org/10.21037/jtd-19-3887

de Man JC (1974) The probability of most probable numbers. Eur J Appl Microbiol 1:67-78. https://doi.org/10.1007/BF01880621

Dhillon J, Lowrie DB, Mitchison DA (2004) Mycobacterium tuberculosis from chronic murine infections that grows in liquid but not on solid medium. BMC Infect Dis 4:4-7. https://doi.org/ 10.1186/1471-2334-4-51

Dutta AK, Choudhary E, Wang X, Záhorszka M, Forbak M, Lohner P, Jessen HJ, Agarwal N, Kordulákova J, Jessen-Trefzer C (2019) Trehalose conjugation enhances toxicity of photosensitizers against mycobacteria. ACS Cent Sci 5:644-650. https://doi.org/10.1021/ acscentsci.8b00962

Feese E, Ghiladi RA (2009) Highly efficient in vitro photodynamic inactivation of Mycobacterium smegmatis. J Antimicrob Chemother 64: 782-785. https://doi.org/10.1093/jac/dkp278

Gong N, Tan Y, Li M, Lu W, Lei X (2016) ALA-PDT combined with antibiotics for the treatment of multiple skin abscesses caused by Mycobacterium fortuitum. Photodiagn Photodyn Ther 15:70-72. https://doi.org/10.1016/j.pdpdt.2016.05.009

Gonzalez-santiago TM, Drage LA (2015) Nontuberculous mycobacteria skin and soft tissue infections. Dermatol Clin 33:563-577. https:// doi.org/10.1016/j.det.2015.03.017

Guffey JS, Payne W, James L (2013) Inactivation of Mycobacterium smegmatis following exposure to 405-nanometer light from a supraluminous diode array. Wounds 25:131-135

Guffey J, Payne W, Martin K, James L, Qian Z (2014) Inhibition of Mycobacterium smegmatis using near-IR and blue light. Int J Res Med Sci 2:42. https://doi.org/10.5455/2320-6012.ijrms20140209

Guterres KB, Rossi GG, Menezes LB, Anraku de Campos MM, Iglesias BA (2019) Preliminary evaluation of the positively and negatively charge effects of tetra-substituted porphyrins on photoinactivation of 
rapidly growing mycobacteria. Tuberculosis $117: 45-51$. https://doi. org/10.1016/j.tube.2019.06.001

Guterres KB, Rossi GG, de Campos MM k A, Moreira KS, Burgo TAL, Iglesias BA (2020) Metal center ion effects on photoinactivating rapidly growing mycobacteria using water-soluble tetra-cationic porphyrins. BioMetals 33:269-282. https://doi.org/10.1007/ s10534-020-00251-3

Hamblin M, Hasan T (2004) Photodynamic therapy: a new antimicrobial approach to infectious disease? Photochem Photobiol Sci 3:436450. https://doi.org/10.1039/b311900a.Photodynamic

Harris F, Pierpoint L (2012) Photodynamic therapy based on 5aminolevulinic acid and its use as an antimicrobial agent. Med Res Rev 32:1292-1327. https://doi.org/10.1002/med

Huo D, Gao J, Guo B, Ding Y, He J, Yu H, Zhou Z, Hu Y (2013) Silver nanoshells as tri-mode bactericidal agents integrating long term antibacterial, photohyperthermia and triggered $\mathrm{Ag}+$ release capabilities. RSC Adv 3:10632-10638. https://doi.org/10.1039/c3ra40417j

Jori G, Fabris C, Soncin M, Ferro S, Coppellotti O, Dei D, Fantetti L, Chiti G, Roncucci G (2006) Photodynamic therapy in the treatment of microbial infections: basic principles and perspective applications. Lasers Surg Med 38:468-481. https://doi.org/10.1002/lsm. 20361

Kamkaew A, Lim SH, Lee HB, Kiew LV, Chung LY, Burgess K (2013) BODIPY dyes in photodynamic therapy. Chem Soc Rev 1:77-88. https://doi.org/10.1039/c2cs35216h

Kaprelyants A, Salina E, Makarov V (2018) How to kill dormant Mycobacterium tuberculosis. Int J Mycobacteriol 7:399-400. https://doi.org/10.4103/ijmy.ijmy

Kharkwal GB, Sharma SK, Huang Y, Dai T (2011) Photodynamic therapy for infections: clinical applications. Lasers Surg Med 43:755767. https://doi.org/10.1002/lsm.21080.Photodynamic

Kudykina YK, Shleeva MO, Artsabanov VY, Suzina NE, Kaprelyants AS (2011) Generation of dormant forms by Mycobacterium smegmatis in the poststationary phase during gradual acidification of the medium. Microbiology 80:638-649. https://doi.org/10.1134/ s0026261711050080

Lian C, Piksa M, Yoshida K, Persheyev S, Pawlik K, Matczyszyn K, Samuel IDW (2019) Flexible organic light-emitting diodes for antimicrobial photodynamic therapy. NPJ Flex Electron 3:18. https:// doi.org/10.1038/s41528-019-0058-0

Liu Y, Qin R, Zaat SAJ, Breukink E, Heger M (2015) Antibacterial photodynamic therapy: overview of a promising approach to fight antibiotic-resistant bacterial infections. J Clin Transl Res 1:140-167

Maisch T (2007) Revitalized strategies against multi-resistant bacteria: antimicrobial photodynamic therapy and bacteriophage therapy. Anti Cancer Agents Med Chem 6:145-150

Malik ZVI, Hanania J, Nitzan Y (1990) New trends in photobiology (Invited Review ) Bactericidal effects of photoactivated porphyrins - an alternative approach to antimicrobial drugs. J Photochem Photobiol B Biol 5:281-293

Moghissi K, Dixon K (2003) Is bronchoscopic photodynamic therapy a therapeutic option in lung cancer? Eur Respir J 22:535-541. https:// doi.org/10.1183/09031936.03.00005203

Møller KI, Kongshoj B, Philipsen PA, Thomsen VO, Wulf HC (2005) How Finsen's light cured lupus vulgaris. Photodermatol Photoimmunol Photomed 21:118-124. https://doi.org/10.1111/j. 1600-0781.2005.00159.x

Mukamolova GV, Turapov O, Malkin J, Woltmann G, Barer MR (2010) Resuscitation-promoting factors reveal an occult population of tubercle bacilli in sputum. Am J Respir Crit Care Med 181:174-180. https://doi.org/10.1164/rccm.200905-06610C

Murdoch LE, Maclean M, Endarko E, MacGregor SJ, Anderson JG (2012) Bactericidal effects of $405 \mathrm{~nm}$ light exposure demonstrated by inactivation of Escherichia, Salmonella, Shigella, Listeria, and Mycobacterium species in liquid suspensions and on exposed surfaces. SciWorld J 2012:137805-137808. https://doi.org/10. $1100 / 2012 / 137805$

Nechaeva OB (2018) TB situation in Russia. Tuberc Lung Dis (In Russ) 96:15-24

Nikitushkin VD, Shleeva MO, Zinin AI, Trutneva KA, Ostrovsky DN, Kaprelyants AS (2016) The main pigment of the dormant Mycobacterium smegmatis is porphyrin. FEMS Microbiol Lett 363:1-8. https://doi.org/10.1093/femsle/fnw206

O'Riordan K, Sharlin DS, Gross J, Chang S, Errabelli D, Akilov OE, Kosaka S, Nau GJ, Hasan T (2006) Photoinactivation of mycobacteria in vitro and in a new murine model of localized Mycobacterium bovis BCG-induced granulomatous infection. Antimicrob Agents Chemother 50:1828-1834. https://doi.org/10. 1128/AAC.50.5.1828-1834.2006

O’Riordan K, Akilov OE, Chang SK, Foley JW, Hasan T (2007) Realtime fluorescence monitoring of phenothiazinium photosensitizers and their anti-mycobacterial photodynamic activity against Mycobacterium bovis BCG in in vitro and in vivo models of localized infection. Photochem Photobiol Sci 6:1117-1123. https://doi. org/10.1039/b707962a

Oppezzo OJ, Forte Giacobone AF (2018) Lethal effect of photodynamic treatment on persister bacteria. Photochem Photobiol 94:186-189. https://doi.org/10.1111/ijlh.12426

Peddireddy V, Doddam SN, Ahmed N (2017) Mycobacterial dormancy systems and host responses in tuberculosis. Front Immunol 8:1-19. https://doi.org/10.3389/fimmu.2017.00084

Romanova NA, Brovko LY, Moore L, Pometun E, Savitsky AP, Ugarova NN, Griffiths MW (2003) Assessment of photodynamic destruction of Escherichia coli O157: $\mathrm{H} 7$ and Listeria monocytogenes by using ATP bioluminescence. Appl Environ Microbiol 69:6393-6398. https://doi.org/10.1128/AEM.69.11.6393

Rossi GG, Guterres KB, da Silveira CH, Moreira KS, Burgo TAL, Iglesias BA, de Campos MMA (2020) Peripheral tetra-cationic $\mathrm{Pt}(\mathrm{II})$ porphyrins photo-inactivating rapidly growing mycobacteria: First application in mycobacteriology. Microb Pathog 148:104455. https://doi.org/10.1016/j.micpath.2020.104455

Shih MH, Huang FC (2011) Effects of photodynamic therapy on rapidly growing nontuberculous mycobacteria keratitis. Investig Ophthalmol Vis Sci 52:223-229. https://doi.org/10.1167/iovs.105593

Shim I, Choi M, Min Y, Seok KH, Kim JK, Jeong JY, Oak CH, Park I (2016) Effect of methylene blue-mediated photodynamic therapy on wild-type and ciprofloxacin-resistant Mycobacterium smegmatis. J Bacteriol Virol 46:27-35. https://doi.org/10.4167/jbv.2016.46.1.27

Shleeva MO, Bagramyan K, Telkov MV, Mukamolova GV, Young M, Kell DB, Kaprelyants AS (2002) Formation and resuscitation of "non-culturable" cells of Rhodococcus rhodochrous and Mycobacterium tuberculosis in prolonged stationary phase. Microbiology 148:1581-1591. https://doi.org/10.1099/00221287$148-5-1581$

Shleeva MO, Kudykina YK, Vostroknutova GN, Suzina NE, Mulyukin AL, Kaprelyants AS (2011) Dormant ovoid cells of Mycobacterium tuberculosis are formed in response to gradual external acidification. Tuberculosis 91:146-154. https://doi.org/10.1016/j.tube.2010.12. 006

Shleeva MO, Savitsky AP, Nikitushkin VD, Solovyev ID, Kazachkina NI, Perevarov VV, Kaprelyants AS (2019) Photoinactivation of dormant Mycobacterium smegmatis due to its endogenous porphyrins. Appl Microbiol Biotechnol 103:9687-9695. https://doi.org/10. 1007/s00253-019-10197-3

Shleeva MO, Savitsky AP, Nikitushkin VD, Soloviev ID, Trutneva KA (2020) Effect of photodynamic inactivation against dormant forms and active growing cells of Mycobacterium smegmatis. Appl Biochem Microbiol 56:242-249. https://doi.org/10.1134/ S000368382003014X 
Sun K, Yang H, Huang X, Gong N, Qin Q, Lu W, Lei X (2017) ALAPDT combined with antibiotics for the treatment of atypical mycobacterial skin infections: Outcomes and safety. Photodiagn Photodyn Ther 19:274-277. https://doi.org/10.1016/j.pdpdt.2017. 06.015

Sung N, Back S, Jung JH, Kim KH, Kim JK, Lee JH, Ra Y, Yang HC, Lim C, Cho S, Kim K, Jheon S (2013) Inactivation of multidrug resistant (MDR)- and extensively drug resistant (XDR)Mycobacterium tuberculosis by photodynamic therapy. Photodiagn Photodyn Ther 10:694-702. https://doi.org/10.1016/j. pdpdt.2013.09.001

Surdel MC, Horvath DJ, Lojek LJ, Fullen AR, Simpson J, Dutter BF, Salleng KJ, Ford JB, Jenkins JL, Nagarajan R, Teixeira PL, Albertolle M, Georgiev IS, Jansen ED, Sulikowski GA, Lacy DB, Dailey HA, Skaar EP (2017) Antibacterial photosensitization through activation of coproporphyrinogen oxidase. PNAS 114: E6652-E6659. https://doi.org/10.1073/pnas.1700469114

Tim M (2015) Biology strategies to optimize photosensitizers for photodynamic inactivation of bacteria. J Photochem Photobiol B Biol 150:2-10. https://doi.org/10.1016/j.jphotobiol.2015.05.010

Usacheva M, Layek B, Nirzhor SSR, Prabha S (2016) Nanoparticlemediated photodynamic therapy for mixed biofilms. J Nanomater 6:1-11. https://doi.org/10.1155/2016/4752894
Wainwright M (1998) Photodynamic antimicrobial chemotherapy (PACT). J Antimicrob Chemother 42:13-28

Wainwright M (2009) Photoantimicrobials — So what's stopping us? Photodiagn Photodyn Ther 5:167-169. https://doi.org/10.1016/j. pdpdt.2009.10.007

Wainwright M, Maisch T, Nonell S, Plaetzer K, Almeida A, Tegos GP, Hamblin MR (2017) Photoantimicrobials - are we afraid of the light? Lancet Infect Dis 17:e49-e55

Wiegell SR, Kongshoj B, Wulf HC (2006) Mycobacterium marinum infection cured by photodynamic therapy. Arch Dermatol 142: 1241-1242. https://doi.org/10.1001/archderm.142.9.1241

Yin R, Agrawal T, Khan U, Gupta GK, Rai V, Huang Y-Y, Hamblin MR (2015) Antimicrobial photodynamic inactivation in nanomedicine: small light strides against bad bugs. Nanomedicine 10:2379-2404. https://doi.org/10.2217/nnm.15.67

Yoo SW, Oh G, Ahn JC, Chung E (2021) Non-oncologic applications of nanomedicine-based photo-therapy. Biomedicines 9:113

Publisher's note Springer Nature remains neutral with regard to jurisdictional claims in published maps and institutional affiliations. 